\section{Hot-button issues for Endangered Species Act reauthorization}

\author{
Patrick Y. O'Brien
}

only to biological diversity but also to ourselves. The biodiversity that surrounds us provides us with food, fiber, medicine and energy. The accumulation of this biodiversity has been a very slow process when measured in human timescales. Biodiversity is the product of a vast history of evolutionary change - about 3.5 billion years. The colonization of the terrestrial environment by lifeforms began approximately 500 to 600 million years ago, and during this most recent $10 \%$ of evolutionary history all of the diverse forms of terrestrial life that comprise our environment appeared. We can not repopulate our world with species that have been lost, nor can we expect to regain the use of lost genetic variants within the timescale of human existence.

To gain perspective on our biological resources and to formulate wise strategies for managing our world, we must consider the following questions: What do we know about the processes that have produced the biological diversity of our world? And how have we attempted to place a value on biological diversity through our conservation activities?

\section{Timescales and diversity}

How long does it take to acquire the unique genetic attributes that mark distinct species? The temporal thread that binds generations is the transmission of the hereditary information encoded in DNA (deoxyribonucleic acid). The preservation of form and function depends on a highly efficient system for the replication of DNA, so that the information transfer from one generation to the next is nearly errorfree. Paradoxically, some errors are essential to provide evolutionary flex-

continued on page 37 ter often conflicts with the habitat needs of other species, which means This is the basic friction point that sparks most of the issues included in

Twenty-two years after its passage and its future is uncertain. More than vamp the ESA, especially to relieve burdens on private landowners. In gent mandates on public agencies as well as on private parties, environmentalists feel that it should be strengthened because humans are placing increasing stress on ecosysA variety of measures, some already embraced in policies adopted by Secretary of Interior Bruce Babbitt to depopulation declines in a number of species with popular appeal such as the bald eagle, the peregrine falcon, the grizzly bear and the timber wolf. Despite public surveys which show that most Americans support the

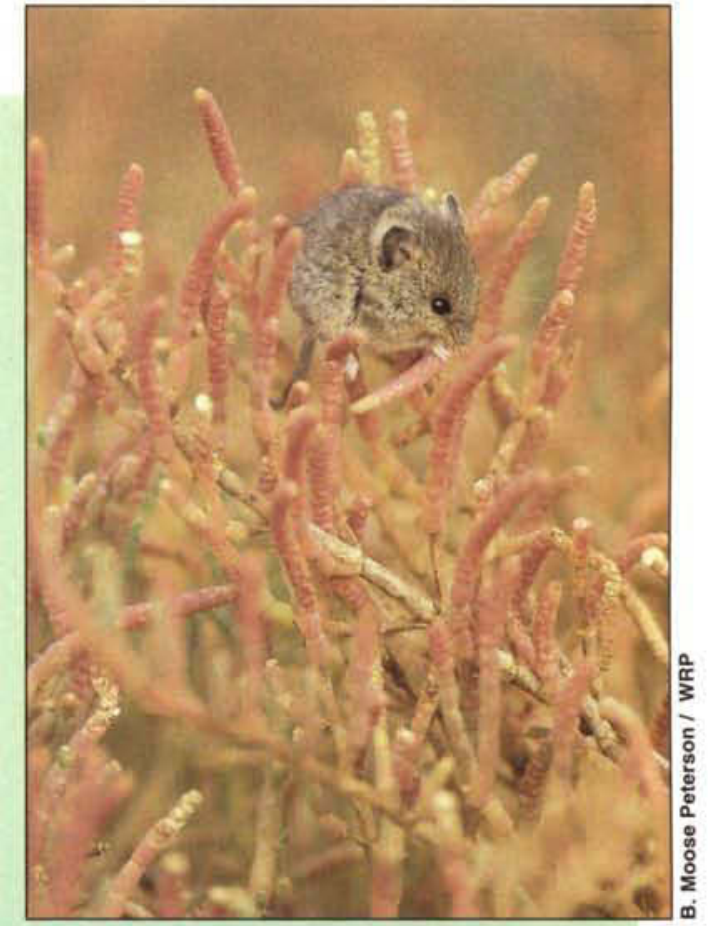

The Endangered Species Act (ESA) establishes protection of threatened and endangered species as a national goal. However, human use of land and wathat protective measures can interfere with economic development and other socially beneficial public works projects. the debate over reauthorizing the ESA. in 1973, the ESA is under heavy attack ever before, Congress is inclined to recontrast, the ESA's defenders feel that many of the proposed reforms will increase the likelihood of species' extinction. Although the ESA imposes strintems that support endangered species. fuse the mounting pressure for reform, could make the ESA more palatable to private landowners, while retaining its basic protective structure and features.

The ESA was originally inspired by
Conflicts have arisen over protection of habitat for endangered species including the salt marsh harvest mouse.

ESA's goals, many people view the law itself as inflexible, unfair to private landowners, unresponsive to certain social and economic factors, marginally successful, and a surrogate for other agendas. These arguments have all been made before, but last fall the public signaled a change in sentiment by electing legislators who were receptive to them.

One controversial aspect of the ESA is that in addition to protecting the highly visible species that appeal to the public, the Act also protects relatively obscure species. When the presence of an obscure species restricts the use of land or water, it creates controversy. Examples abound: in California alone, the Delta smelt has disrupted water deliveries to Central Valley agriculture; the Stephens and Tipton kangaroo rats have restricted cultivation practices in Southern California and the San Joaquin Valley, respectively; the California gnatcatcher has created tremendous uncertainty over the future of real estate development in coastal southern counties; and the northern spotted owl has dampened timber harvesting in the north.

Another controversial aspect of the ESA is that it allows the listing of plant 
and animal subspecies as well as of distinct population segments of vertebrate animals. This aspect has allowed for protection of the bald eagle, southern sea otter, timber wolf and grizzly bear in the lower 48 states even though healthy populations of the same species exist in Canada and Alaska. In addition, scientists disagree about whether some groups of animals, such as the California gnatcatcher and Alabama sturgeon, should qualify as subspecies and therefore be accorded legal protection. Subspecies definitions are often subjective because there is little scientific consensus about what criteria should be applied to what taxonomic groupings.

Some ESA critics want to protect most plants and animals only at the species level, partly because it is difficult to identify subspecies and we lack sufficient data to understand their contribution to genetic variability in most cases. Many scientists counter that protecting subspecies is very likely to increase a species' genetic variability, thus fostering its adaptive potential and survival. They feel that methods for identifying distinct groupings should be improved to make this practice more reliable and credible.

ESA reformists also criticize another aspect of its implementation: disproportionately heavy expenditures on a relatively few species. The single species emphasis has probably been needed to save the California condor, whooping crane, black-footed ferret, Puerto Rican parrot, and Florida panther, whose numbers are still dangerously low. But ESA defenders and critics generally agree that management plans focusing on individual species are inadequate. Multispecies or ecosystemlevel planning would reduce the need for individual species listings, which produce added layers of regulatory complexity. However, due to their different objectives, ESA defenders and reformists will undoubtedly push for different mechanisms to implement multispecies plans.

Another point of contention is whether or not to consider the costeffectiveness of protecting species. Re- cent court settlements have required the U.S. Fish and Wildlife Service to accelerate its schedule for making decisions about listing several hundred high priority candidate species. This faster listing pace has intensified pressure to justify the cost-effectiveness of species protections. Environmentalists feel that cost-benefit analysis would put species at a major disadvantage because their intangible value has already been heavily discounted in the face of economic growth, and that making further tradeoffs would aggravate extinction risk.

The ESA requires federal agencies to ensure that actions they fund, authorize, or carry out are not likely to jeopardize threatened or endangered species, or their critical habitat. Critical habitat is considered those specific areas containing the physical and biological features essential for the conservation of the species. This "non-jeopardy" requirement is under siege by those who think that federal agencies should have more discretion to balance conservation objectives with their other responsibilities such as regulating timber harvests, generating electric power, and distributing water. Environmentalists fear that compromising the non-jeopardy requirement will create irreparable tears in the safety net the ESA affords for imperiled species.

Finally and perhaps most importantly, Congress will have to determine whether and how to regulate habitat on private lands. This comes about because Section 9 of the ESA prohibits "take" of endangered species and by regulation, threatened species. The ban on species take does not distinguish between public and private lands. Most of the unlawful actions included under the definition of "take" cause direct injury or mortality such as hunting, shooting, wounding, killing, capturing and so on. However, "take" also covers "harm" which has been interpreted in regulation to include disturbance of habitat that kills or injures wildlife by significantly impairing essential behavior patterns such as breeding, feeding or sheltering. Last summer the Supreme Court affirmed this interpretation in its decision on Sweet Home Chapter v. Babbitt, which challenged the regulatory definition of harm.

While it is clear that conserving species depends on protecting their habitat, many advocates of private landowner rights view the protection of habitat on private land as excessive intrusion by the federal government. In a move widely hailed by ESA reformists, the House of Representatives recently passed a bill that would require compensation for landowners who suffer greater than $20 \%$ loss of property value due to government regulations. The Senate has not yet taken action on this measure.

Because so many species needing protection occur on private lands, new approaches are urgently needed to encourage cooperation among landowners. Secretary of Interior Babbitt has recently tried to show the ESA can be flexible enough to allay at least some landowners concerns. His "no surprises" and small landowner exemption policies attempt to ease the regulated community's fears about the barriers created when a listed species is found in the path of a development project. "No surprises" aims to assure landowners that conservation planning efforts that consider unlisted candidate species will not be invalidated if these species are later listed. Proposed federal rules would also create an exemption from the taking ban on threatened species for certain small projects. Reformists say that these policies are a good start but that they need to go further and be memorialized in legislation. Some environmentalists view these initiatives as helpful to resolving ESA conflicts while others feel they are useless attempts to appease landowners in the face of political pressure.

In addition, many feel that the current law creates perverse incentives for landowners to eliminate habitat out of fear that threatened and endangered species will occur on their property. This is clearly counterproductive and needs to be outweighed by incentives to protect habitat. Ways of easing the burden on private landowners and 
of increasing their confidence in the ESA include:

1. Encouraging voluntary conservation management agreements such as tax benefits for committing land to conservation.

2. Providing "safe harbor" exemptions when listed species colonize protected habitat.

3. Offering habitat credit trading systems that enable habitat units to be readily bought and sold in order to facilitate both mitigation and conservation objectives.

4. Writing restrictions that can be relaxed when local conservation planning goals are met.

5. Tailoring "take" rules to specific land use activities such as oil well drilling, plugging and abandonment operations.

6. Authorizing general permits for certain categories of ongoing operations and maintenance activities such as right of way or fire safety clearances that have minimal adverse effects.

7. Providing public funding for habitat conservation planning efforts.

8. Passing an amendment to the ESA that memorializes the "no surprises" policy and extends it by stipulating that no newly listed species will invalidate existing conservation agreements.

10. Expediting small project permits by amending the Section 10(a) incidental take permit process to eliminate Environmental Assessments, internal Section 7 consultations and multiple levels of administrative review for small projects that do not trigger interagency consultations.

11. Stressing and including greater landowner participation in recovery programs.

The above actions would also reduce the need to compensate landowners for economic loss, also a necessary feature of ESA administration, but preferably the one of last resort.

P.Y. O'Brien is Team Leader, Ecology, Cheoron Research and Technology Company, Richmond. continued from page 35

ibility. The ultimate source of biological diversity derives from mutational change in DNA molecules.

Owing to the powerful tools of molecular biology, our understanding of the genetic dimension of evolutionary change has advanced enormously over the past decade. These tools have provided us with a direct means of studying the pattern of mutational changes in DNA molecules among diverse life forms. Based on comparative studies, we now know that the error rate for DNA replication is very low (approximately $5 \times 10^{-9}$ base substitutions per nucleotide per year) (Nei 1987). We have also learned that a number of mechanisms cause mutational change, including the insertion and deletion of DNA sequences and the transposition of DNA sequences (e.g., with respect to the chloroplast genome, see Clegg, et al. 1994).

How can we learn about evolutionary time scales from the analysis of DNA sequence differences either among species or among individuals within a species? If we can determine the number of mutations that separate different species and if the mutation rate is constant, we can calculate the time it took to accumulate the observed level of mutational divergence. This notion of a molecular clock has been widely employed in evolutionary biology. To cite but one example of a molecular clock argument, it is estimated from the accumulation of mutational change in molecules that the monocotyledonous class of flowering plants (e.g., grasses, palms, orchids) separated from within the dicotyledonous class (e.g., cotton, sunflowers, apple trees and so on) approximately 200 million years ago (Wolfe et al. 1989).

Let us move from these ancient events in terrestrial evolution to the accumulation of genetic diversity within species. A commonly accepted definition of species is a group of individuals that are able to breed with each other (Mayr 1963). As a consequence, the members of a species share a common gene pool. As the populations that compose a species diverge from one another through time, barriers to reproduction begin to emerge. These include chromosomal rearrangements, behavioral divergence and changes in flowering time. New daughter species are born. The essential characteristic of a species is that the members share a common evolutionary future.

How extensive is the genetic diversity contained within species' gene pools? What factors control diversity levels and how long does it take to reach a given degree of diversity within a species' gene pool? According to biochemical assays of genetic diversity conducted over the past 25 years, most of the 470-plus tested plant species have extensive levels of genetic diversity (Hamrick and Godt 1989) and essentially the same is true of animal species. Plant and animal breeders exploit genetic diversity to improve domesticated species. Similarly, natural selection depends absolutely on genetic diversity to produce adaptive responses to environmental changes.

Levels of genetic diversity within species are controlled by mutation rates, the size of the breeding population (effective population size), and the pattern and strength of natural selection. (Effective population size is calculated as the harmonic mean of population sizes taken over time.) While mutation rates are reasonably constant across most life forms, patterns of effective population size and selection are highly specific and depend on the unique history of the species in question. For example, species that have expanded from glacial refugia may have much larger current numbers but their effective population size is still dominated by the bottleneck imposed by the glacial era. (Refugia are areas of relatively unaltered climate inhabited by plants and animals during a period of continental climatic change.) Hence the time it took to achieve a given degree of genetic diversity depends on the species.

The age of genetic variants within a species can be estimated by coalescence theory (Hudson 1990). Coalescence theory is a recent development in population genetics that relates mutational diversity for a particular gene to past episodes of selection and to the 